
$\$$ Research Square
Preprints are preliminary reports that have not undergone peer review.
They should not be considered conclusive, used to inform clinical practice, or referenced by the media as validated information.

\title{
Umbelliferone ameliorates ulcerative colitis induced by acetic acid via modulation of TLR4/NF-KB- p65/iNOS and PPARY/SIRT1 signaling pathways in rats
}

\section{Basel A Abdel-Wahab ( $\square$ basel_post@msn.com )}

Najran University Faculty of Pharmacy https://orcid.org/0000-0002-5545-6422

\section{Saad A Alkahtani}

Najran University Faculty of Pharmacy

Abdulsalam A Alqahtani

Najran University Faculty of Pharmacy

Emad H.M. Hassanein

Al-Azhar University - Assiut Branch, Faculty of Pharmacy

\section{Research Article}

Keywords: Umbelliferone, acetic acid colitis, oxidative stress, TLR4/NF-kB-p65/iNOS, PPARy, SIRT1

Posted Date: June 22nd, 2021

DOl: https://doi.org/10.21203/rs.3.rs-619327/v1

License: (c) (i) This work is licensed under a Creative Commons Attribution 4.0 International License.

Read Full License 


\section{Abstract}

Ulcerative colitis (UC) is a common chronic, idiopathic inflammatory bowel disease associated with inflammatory perturbation and oxidative stress. Umbelliferone (UMB) is a potent anti-inflammatory and antioxidant coumarin derivative. Depending on the possible mechanisms, we aimed to explore and elucidate the therapeutic potential of UMB on UC-inflammatory response and oxidative injury-induced via intrarectal administration of acetic acid (AA). Rats were assigned into four groups: control group, UMB (30 mg/kg) treated group, colitis model group (2 $\mathrm{ml}$ of $\mathrm{AA} ; 3 \% \mathrm{v} / \mathrm{v})$, and colitis treated with UMB groups. Our results exhibited that UMB improved macroscopic and histological tissue injury caused by the AA. Mechanistically, UMB reduced the elevated TNF-a, IL-6, MPO and VCAM-1 via effective downregulation of TLR-4, NF-KB and iNOS signaling pathway, thereby mediated potent anti-inflammatory effects. Moreover, UMB administration resulted in effective up-regulation of both PPARY and SIRT1 signaling pathways, thereby inhibited both oxidative injury and inflammatory response. Conclusively, UMB protected against AA-induced UC in rats through suppressing of the TLR4/NF-kB-p65/iNOS signaling pathway and promoting the PPARY/SIRT1 signaling. Indeed, our data proved the effectiveness of UMB in UC and introduced it as a potential therapeutic beneficial applicant for clinical application.

\section{Introduction}

Ulcerative colitis (UC) is one of the inflammatory bowel disease (IBD) that represents a global increasingly widespread health problem [1]. UC may cause idiopathic, recurrent inflammation in the colorectal area, as well as the entire gastrointestinal tract [2]. There is evidence that the risk of colorectal cancer is increased by chronic UC [3]. Poor outcomes and the incidence of adverse effects of the currently available treatments [4]. Therefore, novel and effective therapeutic alternatives are urgently needed.

While the exact cause of UC remains unclear, its pathogenesis involves several processes that include neutrophil infiltration, excessive proinflammatory cytokines, and reactive oxygen species (ROS) production [5]. Cytokines such as tumor necrosis factor-alpha (TNF-a), and interleukin-6 (IL-6) are frequently linked with UC [6].

Nuclear factor kappa-B (NF-kB) is a nuclear transcription factor, that plays a crucial role in gastrointestinal homeostasis. Disturbances in the NF-KB pathway initiates inflammatory perturbation and immunity disturbances. NF-KB plays a significant role in UC through the induction of inducible nitric oxide synthase (iNOS), proinflammatory cytokines, and COX-2 expressions in intestinal mucosae [7, 8]. Notably, iNOS and COX-2 activation resulted in obvious large intestinal mucosa damage trough the ROS and reactive nitrogen species (RNS) production along with suppressing the antioxidative system[9]. Moreover, Toll-like receptors (TLRs) play an important role in the primary innate immune responses and inflammation-associated carcinogenesis in the gastrointestinal tract [10], where the up-regulation of TLR4 and induction of the uncontrolled inflammatory response in UC weakens regeneration of the mucosa, resulting in its damage, and consequently may later lead to colon cancer development [11]. Activation of TLRs stimulates the transcription of many inflammatory regulators such as NF-KB and the mitogen- 
activated protein kinase (MAPK) [12]. MAPKs are an important intracellular signal transduction factor family that regulates cell proliferation, division, and apoptosis [13]. The MAPK family members include p38 MAPK, and extracellular signal-regulated kinase (ERK) [14]. Interestingly, MAPK signal activation induce the cytokines release which play a critical role UC pathogenesis [15]. Therefore, targeting the TLR4/NF-KB-p65/iNOS signaling pathway might be a reasonable strategy for management inflammatory diseases, including UC [16].

Additionally, peroxisome proliferator-activated receptor gamma (PPARY) participates in the regulation of mucosal inflammatory injury in UC [17]. Alternatively, PPARY activation effectively downregulates various pro-inflammatory cytokines expressions via potent inhibition of the stimulation of NF-KB [18]. Another important potent inhibitor signaling is the silent information regulator-1 (SIRT1). SIRT1 suppresses the inflammation via MAPK and NF-KB signals inhibition [19]. Recently, activators of SIRT1 have shown protective effects against chemically induced colitis [20].

Umbelliferone (7-hydroxycoumarin; UMB), a coumarin derivative, has a potent anti-inflammatory and antioxidant activities [21]. The therapeutic potentials of UMB in diverse models have been established in previous studies. UMB has shown antidiabetic effect against diabetes mellitus [22], and hepatoprotective activities against hepatic injury [23]. Moreover, UMB showed protective, anti-inflammatory, and antiapoptotic effects against colon cancer in rats [24].

In the present investigation, we aimed to assess whether UMB has a therapeutic beneficial protective effect against the UC induced by $A A$ in rat model and to explore the involved underlying mechanisms via studying the impact of UMB on TLR4/NF-KB-p65/iNOS and PPARY/SIRT1 in these protective effects.

\section{Materials And Methods}

\subsection{Drugs and chemicals}

Umbelliferone (UMB) was purchased from Sigma Aldrich (USA). Acetic acid AA was purchased from ElNaser Pharmaceutical Chemicals Company (Egypt). Rats TNF-a and IL-6 ELISA kits for were purchased from Glory Science Company (USA). Trizol reagent was purchased from Invitrogen Inc, Grand Island, NY (USA). Complementary DNA (cDNA) was purchased from Thermo Scientific Revert Aid (USA). SYBR green master mix was purchased from Bioline, myBio (Ireland) PCR primers for NF-kB-p65, iNOS, TLR4, PPARy, SIRT1, and $\beta$-actin genes were synthesized by Vivantis Technologies (Malaysia). The antibodies used were mouse monoclonal anti-NF-KB-p65, anti-iNOS, anti-TLR4, anti-PPARY, anti-SIRT1 anti-p38MAPK, antiERK1, anti-VCAM-1, and anti- $\beta$-actin antibodies and were purchased from Santa Cruz (USA). BCIP/NBT substrate detection kit was purchased from Genemed Biotechnologies, (USA). Alkaline phosphatase (ALP)-conjugated secondary antibody was purchased from Santa Cruz (USA).

\subsection{Animals}


Adult male Wistar rats, weighing 190-210 g, were obtained from the animal house of the Faculty of Medicine, Assiut University, Egypt. The rats were maintained on a $12 \mathrm{~h}$ dark/light cycle at $24 \pm 2{ }^{\circ} \mathrm{C}$ with free access to food and water ad libitum. Experimental procedure was conducted in accordance with the ethical standards and was approved by the Animal Ethics Committee, Faculty of Medicine, Assiut University, Egypt. Ethics Committee, approval No. (AUN/MED/20/123).

\subsection{Induction of ulcerative colitis}

Animals were starved for at least 24 hours prior to colitis induction, with free access to tap water. The water was held two hours before the procedure on the day of the experiment, then anaesthetized with ketamine (100 mg/kg, i.p.). Ulcerative colitis was induced by administering $2 \mathrm{ml}$ of acetic acid (AA) (3\% $\mathrm{v} / \mathrm{v}$ in saline) by intrarectal route using an elastic catheter (outer diameter of $2 \mathrm{~mm}$ ) under ketamine anesthesia. The catheter was inserted up to $8 \mathrm{~cm}$ rectally in the colon, then rats were kept in a straight position for two min to prevent the outflow of AA. Then to spread the AA totally in the colon, $2 \mathrm{ml}$ of air were injected before removing the catheter. Using the same methods, control rats were given $2 \mathrm{ml}$ of saline instead of acetic acid [25].

\subsection{Experimental protocol}

Forty rats were randomly allocated into four groups (10 rats per group). Group 1: Control group received the vehicle only (The same volume saline instead of AA and the vehicle was delivered only once a day for seven consecutive days). Group 2: (UMB) received UMB suspended in $0.5 \%$ carboxymethyl cellulose (CMC) at a dose of (30 mg/ $\mathrm{kg} /$ day, orally) [26]. once daily for seven days plus the same volume of saline instead of AA solution. Group 3: (AA): UC model (+ve control group) rats were administered the vehicle orally for seven days, and a rectal $A A$ that was given at the end of the $5^{\text {th }}$ day. Group 4: (UMB+AA) received $U M B$ once daily for five days before $A A$ and two days and served as UMB+AA group.

\subsection{Samples preparation}

Twenty-four hours after the last treatment, rats were sacrificed under ketamine anesthesia, and blood samples were collected via cardiac puncture. Blood samples were subjected to centrifugation for obtaining the sera. Sera were stored at $-20^{\circ} \mathrm{C}$ for determination of TNF- $\mathrm{a}$ and IL- 6 levels using ELISA. The $8 \mathrm{~cm}$ distal colon portions of each rat were removed and longitudinally opened, cleaned with cold saline and observed for macroscopic colitis assessment, then cut into three small pieces. One part of the colon was used for histopathological examination and the determination of NF-kB-p65, iNOS, TLR4, PPARy, and SIRT1 proteins expression using immunohistochemical staining. Another part was used for preparation of $20 \%(\mathrm{w} / \mathrm{v})$ homogenates and the supernatants used for assays of $\mathrm{NO}_{2}{ }^{-}$content and MPO activity. Additionally, small part of colonic tissue was stored in RNAlater and used for assessment of NF-kB-p65, iNOS, TLR4, PPARY, and SIRT1 genes using qRT-PCR. Finally, a small part stored in a lysis buffer for western blot analysis of p38MAPK, ERK1, and VCAM-1 proteins.

\subsection{Macroscopic scoring:}




\subsubsection{Evaluation of Disease activity index (DAl):}

Evaluation of the clinical severity of colitis was done through calculation of DAl according previously described method with criteria provided in Table 1[27]. It was calculated according to this equation:

$$
\mathrm{DAI}=\frac{\text { Body weight loss score }+ \text { diarrhea score }+ \text { rectal bleeding score }}{3}
$$

\subsubsection{Colon mucosal injury score (CMIS):}

Furthermore, the percentage of the affected area for which $8 \mathrm{~cm}$ of colon area proximal to the anus with criteria provided in Table 2 [28].

\subsection{Histopathological study}

Histopathological evaluation was done following the method described by Bancroft and Gamble, (2008) [30]. Colon biopsies were fixed with $10 \%$ neutral buffer formalin and embedded in paraffin. The specimens were washed, dehydrated by alcohol, cleared in xylene and embedded in paraffin. For histopathological assessment, $3 \mu \mathrm{m}$ thickness sections were cut and stained with hematoxylin and eosin (H\&E). Histopathological assessment of specimens was performed by an experienced pathologist blindly under the light microscope to the identity of the tested samples.

\subsection{Biochemical assessments}

\subsubsection{Assessment of serum cytokines; TNF- $a$ and IL-6}

Following the manufacturer's instructions and depend on the previously described principles, biochemical estimations of serum TNF-a and IL-6 levels were performed using ELISA kits [31].

\subsubsection{Assessment of $\mathrm{NO}_{2}{ }^{-}$content and MPO activity}

Determination of $\mathrm{NO}_{2}{ }^{-}$content and MPO enzymatic activity were done by methods described by Tasikas (2007) [32] and Krawisz et al. (1984) [33] respectively.

\subsection{Western blot analysis}

Colon tissues were homogenized in Tris lysis buffer and protease inhibitor cocktail (Biospes, China) at $4^{\circ} \mathrm{C}$ for 30 minutes. The residual tissue was discarded by centrifugation at $12000 \mathrm{xg}$ for $10 \mathrm{~min}$ at $4{ }^{\circ} \mathrm{C}$ for 10 minutes. The amount of total protein in each sample was measured according to Bradford's method [34]. A total $50 \mu \mathrm{g}$ of total protein was loaded in each lane and resolved by $10 \%$ SDSpolyacrylamide gel electrophoresis at $150 \mathrm{~V}$ for 50 minutes. SDS-gel was transferred to a PVDF membrane after the completion of the electrophoresis using semi-dry transfer methods [35]. The membranes were blocked with 5\% skimmed milk in TBST buffer at room temperature for 1 hour. The 
membranes were then incubated at $4{ }^{\circ} \mathrm{C}$ with primary antibodies overnight. The membranes were then incubated with the ALP-conjugated secondary antibody for 1 hour. Bands were visualized by BCIP/NBT detection kit. The produced bands were subjected to analysis using image $\mathrm{J} \circledast$ software (National Institutes of Health, Bethesda, USA) related to $\beta$-actin.

\subsection{Immunohistochemical study}

For immunohistochemical investigation, multiple consecutive sections were used. Tissue sections were deparaffinized then treated with $3 \% \mathrm{H} 2 \mathrm{O} 2$ for 10 minutes. Heated in $10 \mathrm{mM}$ citrate buffer at $121^{\circ} \mathrm{C}$ for 30 minutes for antigen retrieval in order to inactivate endogenous peroxidases, then blocked by 5 percent BSA in Tris-buffered saline. Then samples incubation with primary antibodies against NF-kB-p65, iNOS, TLR4, PPARy, and SIRT1 overnight were done. After incubation with HRP-conjugated secondary antibodies for 30 minutes at room temperature, the slides were washed and stained with DAB staining and hematoxylin counterstaining. It was observed that the positive staining of brown color by light microscopy [36]. Using Image $J \circledR$ software, the percentage of area occupied by brown colour was evaluated and the mean area for each slide was obtained.

\subsection{Real-time PCR analysis}

Genes expression estimation of NF-KB-p65, iNOS, TLR4, PPARy, and SIRT1 (Primers sequences were listed in Table (3)) by qRT-PCR. Briefly, Using the Trizol reagent, RNA was extracted from rat colon tissues, and subsequent RNA was transcribed in reverse to CDNA as instructed by the manufacturer. SYBR green was used to assay target genes' expression as previously described [37]. The $\beta$-actin is employed as a reference gene. After PCR amplification, according to the method described by Livak and Schmittgen (2001), the data obtained was analyzed to represent a fold change using the $2^{-\Delta \Delta C T}$ equation [38].

\subsection{Statistical Analysis}

All data are expressed as mean \pm SEM (standard error of the mean). Statistical analysis was performed using the Graph Pad Prism Software Version 6.00 (GraphPad Software, Inc. La Jolla, CA, USA). One-way analysis of variance (ANOVA), followed by Tukey's test, was used to evaluate the statistical significance of differences in each parameter among the different groups, and a $P$-value of $<0.05$ was considered statistically significant.

\section{Results}

\subsection{Effect of UMB on disease activity index, colonic weight/length ratio, and macroscopic colonic examination}

As shown in Figure $1 \mathrm{~A}$., rats that received only AA demonstrated a significant elevation in DAl and CMIS with respect to these of the control rats. Pretreatment with UMB $(30 \mathrm{mg} / \mathrm{kg})$ resulted in a remarkable decrease in the DAI scores and CMIS of the colon of relative to the AA group (Table 4). 


\subsection{Effect of UMB on AA-induced colonic histopathological examination}

Normal control rat (Fig. 1 \& 2A-B) and UMB-treated rats (Fig. 1 \& 2C-D) showed the normal layers of rat's colon. Rats received intrarectal AA showed sever histopathological changes as the desquamated epithelial cells intermingled red blood cells in the colon lumen. The ulcers were observed as deep defects of the lamina epithelialis with its basement membrane. Also, showed severe hemorrhage and marked exhaustion and distortion of goblet cells of the intestinal glands. Well-expressed hyperemia of blood vessels and mixed inflammatory cellular reaction made of neutrophils, eosinophils, and few lymphocytes were observed in the submucosa (Fig. $1 \& 2 \mathrm{E}-\mathrm{G}$ ). On contrast, rats taken UMB greatly attenuated these histopathological abrasions and showed intact mucosa with minimal cellular reaction in the submucosa. The absence of desquamated cells in the colon lumen and intact mucosa were observed with apparent healthy goblet cells with a minimal cellular reaction in the submucosa (Fig. 1 \& $2 \mathrm{H}-\mathrm{I})$.

\subsection{Effect of UMB on proinflammatory cytokines; TNF-a, IL-6 levels as well as MPO enzymatic activity and nitrite content.}

Rectal administration of AA-induced colonic inflammatory response, colitis and significant increase in the proinflammatory cytokines; TNF-a (Fig. 3A) and IL-6 (Fig. 3B) as well as MPO enzymatic activity (Fig. $3 \mathrm{C}$ ) in addition to the $\mathrm{NO}_{2}{ }^{-}$content (Fig. 3D) compared with the control rats. Pretreatment with UMB significantly reduced AA-induced upregulation of the proinflammatory cytokines; TNF-a, IL-6 levels and decreased MPO enzymatic activity and $\mathrm{NO}_{2}{ }^{-}$content relative to AA group.

\subsection{Effect of UMB on colonic p38 MAPK, ERK1, and VCAM-1 level}

To examine the possible role of p38 MAPK, ERK1, and VCAM-1 in AA-induced UC, the protein expressions of p38 MAPK (Fig. 4A), ERK1 (Fig. 4B), and VCAM-1 (Fig. 4C) using Western blotting assay. As represented in Figs. 4 rectal administration of AA resulted in a significant upregulation of p38 MAPK, ERK1, and VCAM-1 expressions in rat colon in comparison with the control group. Alternatively, UMB treatment resulted in remarkable downregulation of p38 MAPK, ERK1, and VCAM-1 compared with the AA group. Moreover, rats treated with UMB alone significant decrease in ERK1 expression compared with the control rats.

\subsection{Effect of UMB on colonic iNOS, TLR4, and NF-KB p65 in AA-induced UC}

To explore the impact of iNOS, TLR4 and NF-KB-p65 (Fig. 5A-D) in the pathological induction of the colonic inflammatory process and ulcerative colitis, the protein expression of these biomarkers was investigated immunohistochemically, and their gene expression was investigated using quantitative PCR analysis.

Results showed that rectal administration of $A A$-induced a significant increase in protein expression of iNOS (Fig. 5B), TLR4 (Fig. 5C), and NF-KB-p65 (Fig. 5D) when compared with the normal 
control group. In parallel with these results, the genes expression also significantly increased when compared with their gene expression levels in the control group. Pretreatment with UMB inhibited the AAinduced increase in both protein and gene expression of iNOS (Fig. 6A), NF-kB-p65 (Fig. 6B) and TLR4 (Fig. 6C) when compared with the AA group. Moreover, animals treated with UMB only exhibited downregulation of these biomarkers compared with the control group.

\subsection{Effect of UMB on colonic PPARY, and SIRT1 expression in AA-induced UC:}

Animals given AA's rectal administration showed a significant decrease in protein and mRNA expression of PPARY (Fig. 7B \& C) and SIRT1 (Fig. 7D \& E), as illustrated in figure 7, in comparison with the normal rats. Conversely, pretreatment with UMB significantly up-regulated both protein and mRNA of PPARY and SIRT1 compared with the AA group.

\section{Discussion}

Lately, IBD could not be cured without treatment and available IBD treatment deals mainly with increasing remission periods and improving patient life quality [39]. Therefore, novel IBD drugs are urgently needed for effective treatment of IBD to replace existing traditional drugs, that cause many harmful side effects. The introduction of these new drugs will lead to more efficient treatment and increase the safety of IBD patients in the treatment process [40]. Accordingly, our investigation was designed on this principle of assessing the therapeutic beneficial effects of UMB in protecting against AA-induced colitis.

Acetic acid (AA)-induced UC is a reasonable widely used model for studying UC [41]. This model is accompanying neutrophil infiltration, inflammation, and oxidative stress that mimics human IBD's pathogenesis [42]. Upon assessing the effect of UMB on colitis manifestation, a significant decrease in the DAI score and CMIS. The results of H\&E examination revealed that UMB markedly reduced the histopathological changes observed in colons of the AA-treated rats.

TNF-a, and IL-6 are key pro-inflammatory cytokines have a critical role in the colonic mucosa inflammation and mucosal barrier destruction [43]. TNF-a is a crucial cytokine linked with continuous immune dysregulation in the inflamed tissues of IBD and generates many chemical inflammatory mediators [44, 45]. Additionally, IL-6 contributes to neutrophil infiltration in chronic inflammatory diseases like colitis [45]. In this study, induction of UC was accompanied by an increase in TNF-a, and IL-6 levels and MPO activity relative to control rats, the effect that was significantly attenuated by UMB. Moreover, AA-treated rats showed significant increase in the MPO activity, an important marker of neutrophil infiltration, which was significantly attenuated by UMB. The reduction of the TNF-a, and IL- 6 levels and MPO activity by UMB in our results indicates the anti-inflammatory effect of UMB, the effect previously reported [24]. Additionally, UC induction by AA is followed by the endothelial VCAM-1 upregulation that is regarded a main cause of leukocyte recruitment to the area of intestinal inflammation [46]. This effect was abrogated by UMB treatment. In the colonic inflammatory conditions, cells and macrophages release TNF-a, which stimulates adhesion molecules like VCAM-1 production, thus enhances leukocytes infiltration into the intestinal mucosa. Therefore, inhibition of these adhesion molecules can successfully 
suppress inflammation [47], which another mechanism via which UMB could inhibit the inflammatory response in AA-induced UC.

Another crucial factor causing colon tissue damage in UC is the oxidative stress [48]. ROS and RNS negatively influence on colonic mucosal membrane organization and resulted in proteins and DNA damages as well as lipid peroxidation [16]. In this study, AA produced a significant increase in both mRNA and protein expression of iNOS that was greatly attenuated by UMB administration. Several experimental studies showed that iNOS expression level is increased in IBD [49,50]. Also, iNOS expression and NO production are elevated in IBD patients' colonic tissue [51]. The increased level of NO and superoxide radicals during UC increases peroxynitrite production, which induces oxidative stress and membrane lipid peroxidation [52]. The ability of UMB to inhibit iNOS expression and activity was previously reported [53]. Expression of iNOS can be stimulated by various factors; among these factors is TNF-a, and NF-KB [54].

NF-KB plays a key role in gut homeostasis and its activation participate in the pathogenesis of IBD in humans [55]. NF-KB activation promotes TNF-a and IL-6 production in UC [56]. In line with these facts, this study showed an increase in both gene and protein expression of NF-KB in colons of animals exposed to $A A$, the effects that were markedly decreased by UMB treatment. The ability of UMB to suppress NF-KB activation and its correlation with the UMB anti-inflammatory effect was previously reported [57].

To furtherly investigate the mechanism of the effect of UMB in colitis and its ability to inhibit NF-KB transcription, we studied the effect on the TLR4/MAPKs signaling pathway, which control of the expression of cytokines and chemokines [58]. Our data demonstrated that AA resulted in significant upregulation in TLR4, p38 MAPK and ERK1. On the contrary, the expression levels of theses markers significantly lowered in colitis rats treated with UMB. Thus, we speculated that UMB might protect against AA-induced colitis through the suppression of the TLR-4/MAPK/NF-KB signaling pathway. MAPKs induce and activate cytokines and NF-KB activation [59]. Pretreatment of animals with UMB downregulated expression of TLR-4 and its downstream p38 and ERK1 indicating that inhibition of NF-KB p65 inflammatory response is mediated via TLR4/MAPK signaling pathway. Previous studies showed the ability of UMB to inhibit the TLR4/MAPK/ NF-KB p65 signaling $[60,61]$.

For further examination of the possible mechanisms of the protective effect of UMB in UC, we studied the possible involvement of the PPARY/SIRT1 signaling pathway. This study showed both the mRNA and protein expression of PPARY and SIRT1 were significantly downregulated by the colonic instillation of AA while significantly restored in colons of animals pretreated with UMB. PPARy controls the expressions of various cytokines by regulating the activity of NF-KB. PPARy expression is downregulated in the colonic epithelium of UC patients. PPARY agonist rosiglitazone effectively treated moderate active distal cases of UC $[18,62]$. Additionally, SIRT1 plays an important role in UC where SIRT1 has been shown to inhibit UC inflammation through suppression of NF-KB activation [63]. Also, SIRT1 suppressed MAPK activation which represents another pathway by which SIRT1 inhibits NF-KB and corresponding inflammation [64]. Moreover, SIRT1 potently inhibited intracellular ROS [65] and stimulate antioxidants' expression [66]. There is an evidence that UMB as a coumarin compound has an antioxidant activity, which is linked to 
the upregulation of SIRT1 [67]. Hence, upregulation of PPARY/SIRT1 signaling, shown in our results also contributes to its antioxidant effect of $\mathrm{UMB}$, which represents additional mechanism for its protective effect against AA-induced UC.

\section{Conclusions}

UMB is a promising candidate for UC treatment. UMB potently mitigated AA-induced colonic injury and inflammation proved by a decrease in macroscopic colon damage score besides the microscopic features of inflammation and colonic tissue damage through its anti-inflammatory activity. UMB inhibited the inflammation through TLR4/NF-KB-p65/iNOS signaling pathway, thereby effectively decreased the expression of cytokines; TNF-a, IL-6, and MPO enzymatic activity. Moreover, UMB upregulated the PPARY/SIRT1 signaling pathway, which inhibits NF-KB-p65 activation and restored antioxidant status. Therefore, our data proved the beneficial efficacy of UMB and introduced it as a promising therapeutic applicant for UC.

\section{Declarations}

Funding: This study was funded by the Deanship of Scientific Research - Najran University- Kingdom of Saudi Arabia for their Financial and Technical support under code number (NU/MID/17/118).

Conflicts of interest: The authors have no conflicts of interest to declare that are relevant to the content of this article.

Availability of data and material: Not applicable

Code availability: Not applicable

\section{Authors' contributions}

All authors contributed to the study conception and design. Material preparation, data collection and analysis were performed by [Basel A. Abdel-Wahab1], [Emad H.M. Hassanein], [Saad A Alkahtan] and [Abdulsalam A. Alqahtani]. The first draft of the manuscript was written by [Basel A. Abdel-Wahab] and [Emad H.M. Hassanein] and all authors commented on previous versions of the manuscript. All authors read and approved the final manuscript.

Ethics approval: Not applicable

Consent to participate: Informed consent was obtained from all individual participants included in the study.

Consent for publication: Not applicable

\section{References}


1. de Souza, H. S., and C. Fiocchi. 2016. Immunopathogenesis of IBD: current state of the art, Nature reviews. Gastroenterology \& hepatology 13 (1): 13-27. https://doi.org/10.1038/nrgastro.2015.186.

2. Novak, E. A., and K. P. Mollen. 2015. Mitochondrial dysfunction in inflammatory bowel disease. Frontiers in cell and developmental biology 3: 62. https://doi.org/10.3389/fcell.2015.00062.

3. Lakatos, P. L., and L. Lakatos, Risk for colorectal cancer in ulcerative colitis: changes, causes and management strategies, World journal of gastroenterology 14(25). 2008. 3937-47, https://doi.org/10.3748/wjg.14.3937.

4. Harbord, M., R. Eliakim, D. Bettenworth, K. Karmiris, K. Katsanos, U. Kopylov, T. Kucharzik, T. Molnár, T. Raine, S. Sebastian, H. T. de Sousa, A. Dignass, and F. Carbonnel. 2017. Third European Evidencebased Consensus on Diagnosis and Management of Ulcerative Colitis. Part 2: Current Management. Journal of Crohn's \& colitis 11 (7): 769-784. https://doi.org/10.1093/ecco-jcc/jjx009.

5. Ko, J. K., and K. K. Auyeung. 2014. Inflammatory bowel disease: etiology, pathogenesis and current therapy. Current pharmaceutical design 20 (7): 1082-1096.

https://doi.org/10.2174/13816128113199990416.

6. Stevens, C., G. Walz, C. Singaram, M. L. Lipman, B. Zanker, A. Muggia, D. Antonioli, M. A. Peppercorn, and T. B. Strom, Tumor necrosis factor-alpha, interleukin-1 beta, and interleukin- 6 expression in inflammatory bowel disease, Digestive diseases and sciences 37(6) (1992) $818-26$, https://doi.org/10.1007/bf01300378.

7. Schottelius, A., A.J.I.j.o.c.d. Baldwin Jr, A role for transcription factor NF-kB in intestinal inflammation, 14(1). 1999. 18-28, https://doi.org/.

8. Yao, D., M. Dong, C. Dai, and S. Wu. 2019. Inflammation and Inflammatory Cytokine Contribute to the Initiation and Development of Ulcerative Colitis and Its Associated Cancer. Inflammatory bowel diseases 25 (10): 1595-1602. https://doi.org/10.1093/ibd/izz149.

9. Bhattacharyya, A., R. Chattopadhyay, S. Mitra, and S. E. Crowe, Oxidative stress: an essential factor in the pathogenesis of gastrointestinal mucosal diseases, Physiological reviews 94(2) (2014) 329 - 54, https://doi.org/10.1152/physrev.00040.2012.

10. Fukata, M., and M. T. Abreu, Role of Toll-like receptors in gastrointestinal malignancies, Oncogene 27(2) (2008) $234-43$, https://doi.org/10.1038/sj.onc.1210908.

11. Cario, E. 2010. Toll-like receptors in inflammatory bowel diseases: a decade later. Inflammatory bowel diseases 16 (9): 1583-1597. https://doi.org/10.1002/ibd.21282.

12. Zhang, G., and S. Ghosh, Toll-like receptor-mediated NF-kappaB activation: a phylogenetically conserved paradigm in innate immunity, The Journal of clinical investigation 107(1) (2001) $13-9$, https://doi.org/10.1172/jci11837.

13. Osaki, L. H., and P. Gama. 2013. MAPKs and signal transduction in the control of gastrointestinal epithelial cell proliferation and differentiation. International journal of molecular sciences 14 (5): 10143-10161. https://doi.org/10.3390/ijms140510143.

14. Cargnello, M., and P. P. Roux. 2011. Activation and function of the MAPKs and their substrates, the MAPK-activated protein kinases. Microbiology and molecular biology reviews: MMBR 75 (1): 50-83. 
https://doi.org/10.1128/mmbr.00031-10.

15. Broom, O. J., B. Widjaya, J. Troelsen, J. Olsen, and O. H. Nielsen, Mitogen activated protein kinases: a role in inflammatory bowel disease? Clinical and experimental immunology 158(3) (2009) $272-80$, https://doi.org/10.1111/j.1365-2249.2009.04033.x.

16. Wang, G., B. Xu, F. Shi, M. Du, Y. Li, T. Yu, and L. Chen, Protective Effect of Methane-Rich Saline on Acetic Acid-Induced Ulcerative Colitis via Blocking the TLR4/NF-KB/MAPK Pathway and Promoting IL-10/JAK1/STAT3-Mediated Anti-inflammatory Response, Oxidative medicine and cellular longevity 2019 (2019) 7850324, https://doi.org/10.1155/2019/7850324.

17. Dubuquoy, L., C. Rousseaux, X. Thuru, L. Peyrin-Biroulet, O. Romano, P. Chavatte, M. Chamaillard, and P. Desreumaux. 2006. PPARgamma as a new therapeutic target in inflammatory bowel diseases. Gut 55 (9): 1341-1349. https://doi.org/10.1136/gut.2006.093484.

18. Chen, F., M. Wang, J. P. O'Connor, M. He, T. Tripathi, and L. E. Harrison, Phosphorylation of PPARgamma via active ERK1/2 leads to its physical association with p65 and inhibition of NFkappabeta, Journal of cellular biochemistry 90(4) (2003) $732-44$, https://doi.org/10.1002/jcb.10668.

19. Sayed, A. M., E. H. M. Hassanein, S. H. Salem, O. E. Hussein, and A. M. Mahmoud. 2020. Flavonoidsmediated SIRT1 signaling activation in hepatic disorders. Life sciences 259: 118173. https://doi.org/10.1016/j.lfs.2020.118173.

20. Zhang, L., H. Xue, G. Zhao, C. Qiao, X. Sun, C. Pang, and D. Zhang. 2019. Curcumin and resveratrol suppress dextran sulfate sodium-induced colitis in mice. Molecular medicine reports 19 (4): 30533060. https://doi.org/10.3892/mmr.2019.9974.

21. Hassanein, E. H. M., A. M. Sayed, O. E. Hussein, and A. M. Mahmoud, Coumarins as Modulators of the Keap1/Nrf2/ARE Signaling Pathway, Oxidative medicine and cellular longevity 2020 (2020) 1675957, https://doi.org/10.1155/2020/1675957.

22. Ramesh, B., and K. V. Pugalendi. 2006. Antihyperglycemic effect of umbelliferone in streptozotocindiabetic rats. Journal of medicinal food 9 (4): 562-566. https://doi.org/10.1089/jmf.2006.9.562.

23. Yin, J., H. Wang, and G. Lu, Umbelliferone alleviates hepatic injury in diabetic $\mathrm{db} / \mathrm{db}$ mice via inhibiting inflammatory response and activating Nrf2-mediated antioxidant, Bioscience reports 38(4) (2018), https://doi.org/10.1042/bsr20180444.

24. Muthu, R., N. Selvaraj, and M. Vaiyapuri. 2016. Anti-inflammatory and proapoptotic effects of umbelliferone in colon carcinogenesis. Human \& experimental toxicology 35 (10): 1041-1054. https://doi.org/10.1177/0960327115618245.

25. Arafa, E. A., W. R. Mohamed, D. M. Zaher, and H. A. Omar. 2020. Gliclazide attenuates acetic acidinduced colitis via the modulation of PPARY, NF-KB and MAPK signaling pathways. Toxicology and applied pharmacology 391: 114919. https://doi.org/10.1016/j.taap.2020.114919.

26. Hassanein, E. H. M., W. R. Mohamed, A. S. Shalkami, M. M. Khalaf, and R. A. M. Hemeida, Renoprotective effects of umbelliferone on methotrexate-induced renal injury through regulation of Nrf-2/Keap-1, P(38)MAPK/NF-KB, and apoptosis signaling pathways, Food and chemical toxicology: 
an international journal published for the British Industrial Biological Research Association 116(Pt B) (2018) 152-160, https://doi.org/10.1016/j.fct.2018.03.041.

27. Niu, X., H. Zhang, W. Li, Y. Wang, Q. Mu, X. Wang, Z. He, and H. Yao, Protective effect of cavidine on acetic acid-induced murine colitis via regulating antioxidant, cytokine profile and NF-kB signal transduction pathways, Chemico-biological interactions 239 (2015) 34-45, https://doi.org/10.1016/j.cbi.2015.06.026.

28. Ghafari, H., N. Yasa, A. Mohammadirad, G. Dehghan, M. J. Zamani, S. Nikfar, R. Khorasani, B. Minaie, and M. Abdollahi, Protection by Ziziphora clinopoides of acetic acid-induced toxic bowel inflammation through reduction of cellular lipid peroxidation and myeloperoxidase activity, Human \& experimental toxicology 25(6) (2006) 325 - 32, https://doi.org/10.1191/0960327105ht626oa.

29. Wallace, J. L., C. M. Keenan, D. Gale, and T. S. Shoupe. 1992. Exacerbation of experimental colitis by nonsteroidal anti-inflammatory drugs is not related to elevated leukotriene B4 synthesis. Gastroenterology 102 (1): 18-27. https://doi.org/10.1016/0016-5085(92)91779-4.

30. Bancroft, J. D., and M. Gamble, Theory and practice of histological techniques, Elsevier health sciences2008.

31. Van Weemen, B., and A.J.F.I. Schuurs, Immunoassay using antigen-enzyme conjugates, 15(3). 1971. 232-236, https://doi.org/.

32. Tsikas, D. 2007. Analysis of nitrite and nitrate in biological fluids by assays based on the Griess reaction: appraisal of the Griess reaction in the L-arginine/nitric oxide area of research. Journal of chromatography. B, Analytical technologies in the biomedical and life sciences 851 (1-2): 51-70. https://doi.org/10.1016/j.jchromb.2006.07.054.

33. Krawisz, J. E., P. Sharon, and W. F. Stenson, Quantitative assay for acute intestinal inflammation based on myeloperoxidase activity. Assessment of inflammation in rat and hamster models, Gastroenterology 87(6). 1984. 1344-50, https://doi.org/.

34. Kruger, N. J. The Bradford method for protein quantitation, The protein protocols handbook, Springer2009, pp. 17-24.

35. Towbin, H., T. Staehelin, and J. Gordon. 1979. Electrophoretic transfer of proteins from polyacrylamide gels to nitrocellulose sheets: procedure and some applications. Proceedings of the National Academy of Sciences of the United States of America 76 (9): 4350-4354. https://doi.org/10.1073/pnas.76.9.4350.

36. Ramos-Vara, J. A., and M. A. Miller. 2014. When tissue antigens and antibodies get along: revisiting the technical aspects of immunohistochemistry-the red, brown, and blue technique. Veterinary pathology 51 (1): 42-87. https://doi.org/10.1177/0300985813505879.

37. Hassanein, E. H. M., A. S. Shalkami, M. M. Khalaf, W. R. Mohamed, and R. A. M. Hemeida. 2019. The impact of Keap1/Nrf2, P(38)MAPK/NF-KB and Bax/Bcl2/caspase-3 signaling pathways in the protective effects of berberine against methotrexate-induced nephrotoxicity. Biomedicine \& pharmacotherapy = Biomedecine \& pharmacotherapie 109: 47-56.

https://doi.org/10.1016/j.biopha.2018.10.088. 
38. Livak, K. J., and T.D.J.m. Schmittgen, Analysis of relative gene expression data using real-time quantitative PCR and the $2-\Delta \Delta C T$ method, 25(4). 2001. 402-408, https://doi.org/.

39. Saniabadi, A. R., T. Tanaka, T. Ohmori, K. Sawada, T. Yamamoto, and H. Hanai, Treating inflammatory bowel disease by adsorptive leucocytapheresis: a desire to treat without drugs, World journal of gastroenterology 20(29) (2014) 9699 - 715, https://doi.org/10.3748/wjg.v20.i29.9699.

40. Triantafillidis, J. K., E. Merikas, and F. Georgopoulos. 2011. Current and emerging drugs for the treatment of inflammatory bowel disease. Drug design, development and therapy 5: 185-210. https://doi.org/10.2147/dddt.S11290.

41. Randhawa, P. K., K. Singh, N. Singh, and A. S. Jaggi, A review on chemical-induced inflammatory bowel disease models in rodents, The Korean journal of physiology \& pharmacology: official journal of the Korean Physiological Society and the Korean Society of Pharmacology 18(4) (2014) $279-88$, https://doi.org/10.4196/kjpp.2014.18.4.279.

42. Low, D., D. D. Nguyen, and E. Mizoguchi. 2013. Animal models of ulcerative colitis and their application in drug research. Drug design, development and therapy 7: 1341-1357. https://doi.org/10.2147/dddt.S40107.

43. Neurath, M. F. Cytokines in inflammatory bowel disease, Nature reviews. Immunology 14(5) (2014) 329 - 42, https://doi.org/10.1038/nri3661.

44. Friedrich, M., M. Pohin, and F. Powrie. 2019. Cytokine Networks in the Pathophysiology of Inflammatory Bowel Disease. Immunity 50 (4): 992-1006. https://doi.org/10.1016/j.immuni.2019.03.017.

45. Neurath, M. F., and S. Finotto, IL-6 signaling in autoimmunity, chronic inflammation and inflammation-associated cancer, Cytokine \& growth factor reviews 22(2) (2011) 83 - 9, https://doi.org/10.1016/j.cytogfr.2011.02.003.

46. Mollà, M., M. Gironella, R. Miquel, V. Tovar, P. Engel, A. Biete, J. M. Piqué, and J. Panés, Relative roles of ICAM- 1 and VCAM- 1 in the pathogenesis of experimental radiation-induced intestinal inflammation, International journal of radiation oncology, biology, physics 57(1) (2003) $264-73$, https://doi.org/10.1016/s0360-3016(03)00523-6.

47. Soriano, A., A. Salas, A. Salas, M. Sans, M. Gironella, M. Elena, D. C. Anderson, J. M. Piqué, and J. Panés, VCAM-1, but not ICAM-1 or MAdCAM-1, immunoblockade ameliorates DSS-induced colitis in mice, Laboratory investigation; a journal of technical methods and pathology 80(10). 2000. 1541-51, https://doi.org/10.1038/labinvest.3780164.

48. Wang, Z., S. Li, Y. Cao, X. Tian, R. Zeng, D. F. Liao, and D. Cao, Oxidative Stress and Carbonyl Lesions in Ulcerative Colitis and Associated Colorectal Cancer, Oxidative medicine and cellular longevity 2016 (2016) 9875298, https://doi.org/10.1155/2016/9875298.

49. Camuesco, D., M. Comalada, M. E. Rodríguez-Cabezas, A. Nieto, M. D. Lorente, A. Concha, A. Zarzuelo, and J. Gálvez, The intestinal anti-inflammatory effect of quercitrin is associated with an inhibition in iNOS expression, British journal of pharmacology 143(7) (2004) 908 - 18, https://doi.org/10.1038/sj.bjp.0705941. 
50. Youn, J., J. S. Lee, H. K. Na, J. K. Kundu, and Y. J. Surh, Resveratrol and piceatannol inhibit iNOS expression and NF-kappaB activation in dextran sulfate sodium-induced mouse colitis, Nutrition and cancer 61(6) (2009) 847 - 54, https://doi.org/10.1080/01635580903285072.

51. Kimura, H., R. Hokari, S. Miura, T. Shigematsu, M. Hirokawa, Y. Akiba, I. Kurose, H. Higuchi, H.

Fujimori, Y. Tsuzuki, H. Serizawa, and H. Ishii. 1998. Increased expression of an inducible isoform of nitric oxide synthase and the formation of peroxynitrite in colonic mucosa of patients with active ulcerative colitis. Gut 42 (2): 180-187. https://doi.org/10.1136/gut.42.2.180.

52. Kim, Y. J., E. H. Kim, and K. B. Hahm. 2012. Oxidative stress in inflammation-based gastrointestinal tract diseases: challenges and opportunities. Journal of gastroenterology and hepatology 27 (6): 1004-1010. https://doi.org/10.1111/j.1440-1746.2012.07108.x.

53. Luo, H., Z. Fan, D. Xiang, Z. Jiang, W. Zhang, L. Gao, and C. Feng. 2018. The protective effect of umbelliferone ameliorates myocardial injury following ischemia-reperfusion in the rat through suppression NLRP3 inflammasome and upregulating the PPAR- $\gamma$. Molecular medicine reports 17 (2): 3404-3410. https://doi.org/10.3892/mmr.2017.8208.

54. Salim, T., C. L. Sershen, and E. E. May. 2016. Investigating the Role of TNF-a and IFN-Y Activation on the Dynamics of iNOS Gene Expression in LPS Stimulated Macrophages. PloS one 11 (6): e0153289. https://doi.org/10.1371/journal.pone.0153289.

55. Zaidi, D., and E. Wine. 2018. Regulation of Nuclear Factor Kappa-Light-Chain-Enhancer of Activated B Cells (NF-k $\beta$ ) in Inflammatory Bowel Diseases. Frontiers in pediatrics 6: 317. https://doi.org/10.3389/fped.2018.00317.

56. He, Z., Q. Zhou, K. Wen, B. Wu, X. Sun, X. Wang, and Y. Chen, Huangkui Lianchang Decoction Ameliorates DSS-Induced Ulcerative Colitis in Mice by Inhibiting the NF-kappaB Signaling Pathway, Evidence-based complementary and alternative medicine: eCAM 2019 (2019) 1040847, https://doi.org/10.1155/2019/1040847.

57. Kim, S. B., M. J. Kang, C. W. Kang, N. H. Kim, H. W. Choi, H. A. Jung, J. S. Choi, and G. D. Kim. 2019. Anti-inflammatory effects of 6 -formyl umbelliferone via the NF-KB and ERK/MAPK pathway on LPS-stimulated RAW 264.7 cells. International journal of molecular medicine 43 (4): 1859-1865. https://doi.org/10.3892/ijmm.2019.4078.

58. Liu, T., L. Zhang, D. Joo, and S. C. Sun, NF-kB signaling in inflammation, Signal transduction and targeted therapy 2 (2017) 17023-, https://doi.org/10.1038/sigtrans.2017.23.

59. Xiao, K., C. Liu, Z. Tu, Q. Xu, S. Chen, Y. Zhang, X. Wang, J. Zhang, C. A. Hu, and Y. Liu, Activation of the NF-KB and MAPK Signaling Pathways Contributes to the Inflammatory Responses, but Not Cell Injury, in IPEC-1 Cells Challenged with Hydrogen Peroxide, Oxidative medicine and cellular longevity 2020 (2020) 5803639, https://doi.org/10.1155/2020/5803639.

60. Wang, D., X. Wang, W. Tong, Y. Cui, X. Li, and H. Sun. 2019. Umbelliferone Alleviates Lipopolysaccharide-Induced Inflammatory Responses in Acute Lung Injury by Down-Regulating TLR4/MyD88/NF-kB Signaling. Inflammation 42 (2): 440-448. https://doi.org/10.1007/s10753-01800953-4. 
61. Hassanein, E. H. M., F. E. M. Ali, M. R. Kozman, and O. A. M. Abd El-Ghafar, Umbelliferone attenuates gentamicin-induced renal toxicity by suppression of TLR-4/NF-KB-p65/NLRP-3 and JAK1/STAT-3 signaling pathways, Environmental science and pollution research international 10.1007/s11356020-11416-5 (2020), https://doi.org/10.1007/s11356-020-11416-5.

62. Pedersen, G., and J. Brynskov, Topical rosiglitazone treatment improves ulcerative colitis by restoring peroxisome proliferator-activated receptor-gamma activity, The American journal of gastroenterology 105(7) (2010) 1595 - 603, https://doi.org/10.1038/ajg.2009.749.

63. Yang, H., W. Zhang, H. Pan, H. G. Feldser, E. Lainez, C. Miller, S. Leung, Z. Zhong, H. Zhao, S. Sweitzer, T. Considine, T. Riera, V. Suri, B. White, J. L. Ellis, G. P. Vlasuk, and C. Loh. 2012. SIRT1 activators suppress inflammatory responses through promotion of p65 deacetylation and inhibition of NF-KB activity. PloS one 7 (9): e46364. https://doi.org/10.1371/journal.pone.0046364.

64. Kauppinen, A., T. Suuronen, J. Ojala, K. Kaarniranta, and A. Salminen. 2013. Antagonistic crosstalk between NF-KB and SIRT1 in the regulation of inflammation and metabolic disorders. Cellular signalling 25 (10): 1939-1948. https://doi.org/10.1016/j.cellsig.2013.06.007.

65. Zhang, J., Q. Song, X. Han, Y. Zhang, Y. Zhang, X. Zhang, X. Chu, F. Zhang, and L. Chu. 2017. Multitargeted protection of acetaminophen-induced hepatotoxicity in mice by tannic acid. International immunopharmacology 47: 95-105. https://doi.org/10.1016/j.intimp.2017.03.027.

66. Olmos, Y., F. J. Sánchez-Gómez, B. Wild, N. García-Quintans, S. Cabezudo, S. Lamas, and M. Monsalve. 2013. SirT1 regulation of antioxidant genes is dependent on the formation of a Fox03a/PGC-1a complex. Antioxidants \& redox signaling 19 (13): 1507-1521. https://doi.org/10.1089/ars.2012.4713.

67. Iside, C., M. Scafuro, A. Nebbioso, and L. Altucci, SIRT1 Activation by Natural Phytochemicals: An Overview, Frontiers in pharmacology 11 (2020) 1225, https://doi.org/10.3389/fphar.2020.01225.

\section{Tables}

Table 1. Criteria for DAI

\begin{tabular}{|llll|}
\hline Score & Weight loss $(\%)$ & Occult blood & Stool consistency \\
\hline 0 & $<0$ & Negative & Normal \\
\hline 1 & $1-5$ & + & \\
\hline 2 & $5-10$ & ++ & Soft \\
\hline 3 & $10-20$ & +++ & \\
\hline 4 & $>20$ & Gross bleeding & Severe Diarrhea \\
\hline
\end{tabular}

Table 2. Criteria for colon mucosal injury score (CMIS) 


\begin{tabular}{|ll|}
\hline Score & Criteria \\
\hline 0 & No damage \\
\hline 1 & Mild hyperemia with small edema and no corrosion or ulcer seen in the mucosal layer \\
\hline 3 & Moderate hyperemia and edema with one corrosion site in the mucosal layer \\
\hline 4 & $\begin{array}{l}\text { Severe hyperemia and edema and inflammation covering the mucosal layer and the size of } \\
\text { the major inflammation does not exceed } 1 \mathrm{~cm}\end{array}$ \\
\hline 5 & $\begin{array}{l}\text { Severe hyperemia and edema with swelling, bleeding, and inflammation covering the } \\
\text { mucosal layer, and the size of the major inflammation covers } \otimes 1 \mathrm{~cm} .\end{array}$ \\
\hline
\end{tabular}

Table 3. The sequence of primers used for mRNA expression quantification by RT-PCR.

\begin{tabular}{|ll|}
\hline Target gene & Sequence (5- 3) \\
NF-kB p65 & F: TTCCCTGAAGTGGAGCTAGGA \\
& R: CATGTCGAGGAAGACACTGGA \\
TLR4 & F: CGAGCCAGAATGAGGACTGG \\
R: TCCCACTCGAGGTAGGTGTT & F: CAGGCTTGGGTCTTGTTAGC \\
& R: CTTGTGGTGAAGGGTGTCGT \\
PPARY & F: GGGACGCTGAAGAAGAGACCTG \\
R: CACAGTCCGGTCAGAAAGTGA & F: CGGTCTGTCAGCATCATCTTCC \\
& R: CGCCTTATCCTCTAGTTCCTGTG \\
\hline B-actin & F: CCACCATGTACCCAGGCATT \\
& R: ACGCAGCTCAGTAACAGTCC \\
\hline
\end{tabular}

Table 4. Effect of REB on DAI and CMIS of AA-induced UC

\begin{tabular}{|lllll|}
\hline & Control & UMB & AA & UMB+AA \\
\hline DAI & 0 & 0 & $3.83 \pm 0.24^{a}$ & $2.4 \pm 0.17^{\mathrm{a}, \mathrm{b}}$ \\
\hline CMIS & 0 & 0 & $4.94 \pm 0.30^{\mathrm{a}}$ & $3.42 \pm 0.16^{\mathrm{a}, \mathrm{b}}$ \\
\hline
\end{tabular}

\section{Figures}



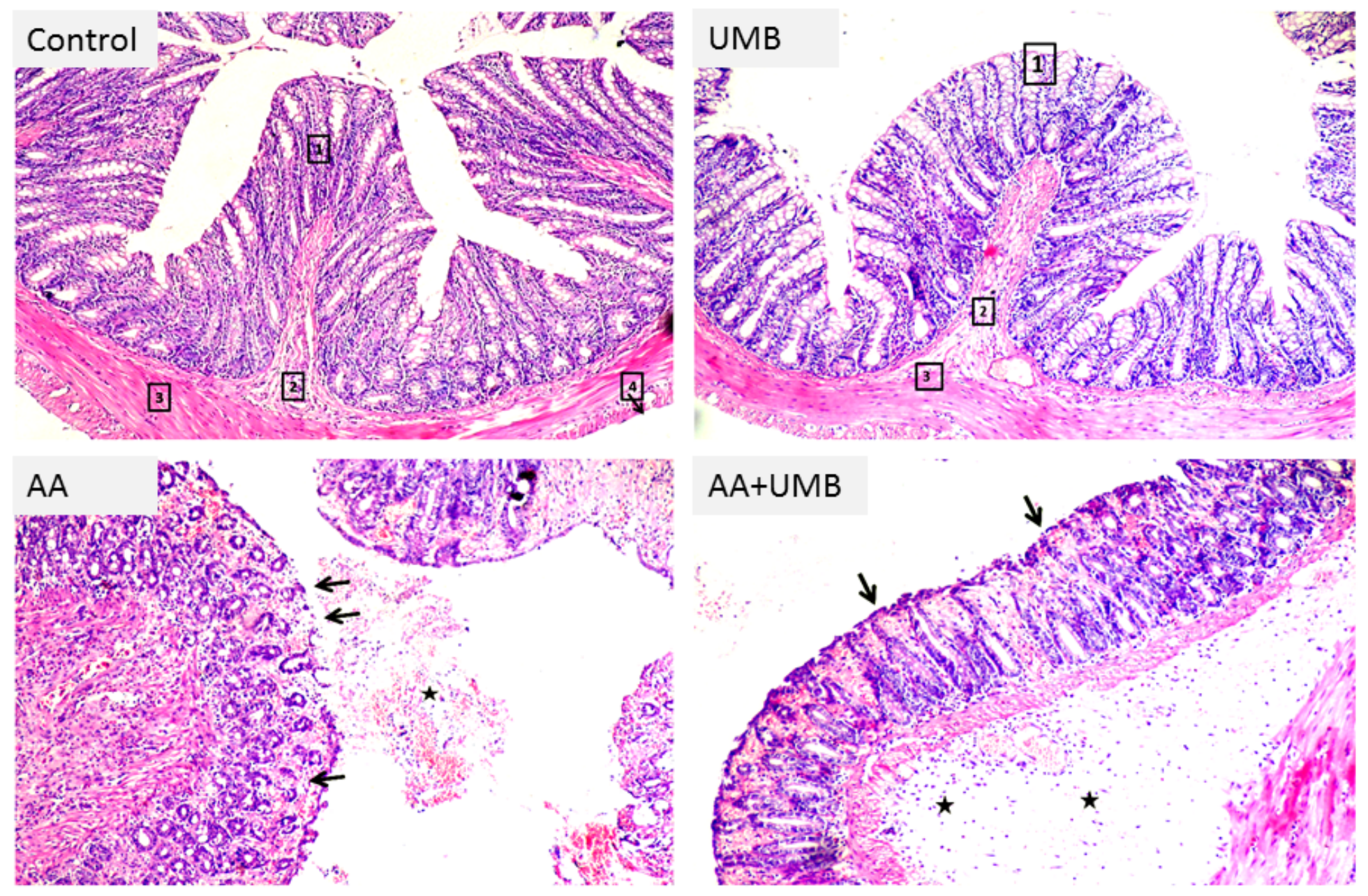

Figure 1

Effect of UMB in histopathological changes-induced by AA in UC at lower magnifications. Normal control colon and UMB showing the mucosa (1), submucosa (2), muscularis (3) and serosa (4). On the other hand, intrarectal administration showing desquamated epithelial cells intermingled red blood cells in the colon lumen (star) and ulcers (arrow). Alternatively, treatment with UMB exhibiting intact mucosa(arrow) minimal cellular reaction in the submucosa (star). (H\&E x100) 

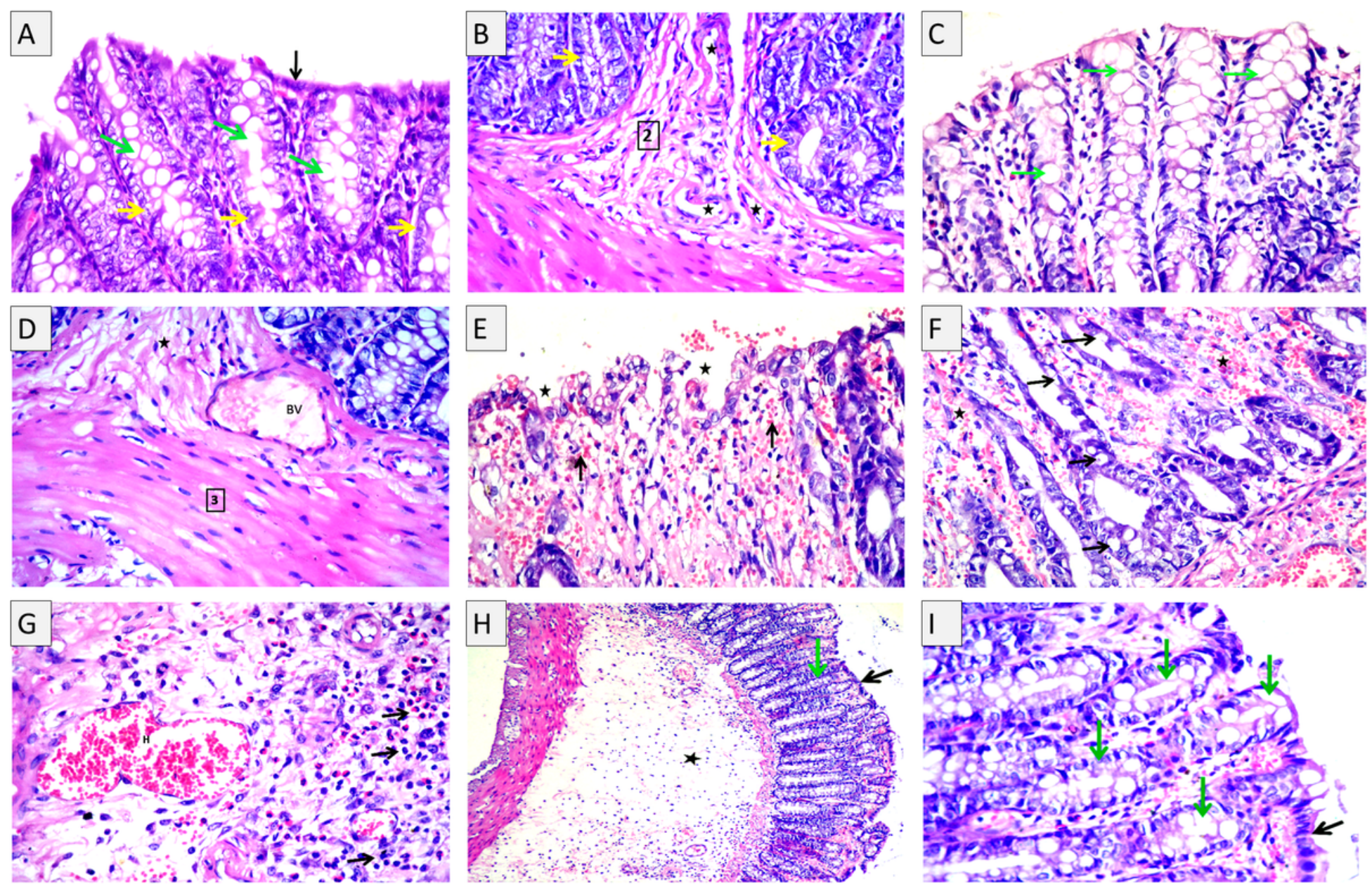

Figure 2

Effect of UMB in histopathological changes-induced by AA in UC at higher magnifications. Normal control colon showing the mucosa, simple columnar epithelium (black arrow), goblet cells (green arrow) and vertical intestinal glands (yellow arrow) (A). Also, showing the submucosa (2), made of dense connective tissue containing large diameter blood vessels (star) and vertical and horizontal intestinal glands (yellow arrow) (B). Regarded to UMB treatment, the results showing the normal layers of colon, mucosa (1), submucosa (2), muscularis (3) (C) as well as normal appearance of intestinal glands and goblet cells (B) as well as showing the normal appearance of submucosa (star) and blood vessels (BV), and muscularis (3) (D). On the other side intrarectal administration of AA resulted in desquamated epithelial cells intermingled red blood cells in the colon lumen (star) and ulcers (arrow) (E). Another view showing severe hemorrhage (star) and marked exhaustion of goblet cells (arrow) of the intestinal glands (F). Also, wellexpressed hyperemia of blood vessels $(\mathrm{H})$ and mixed inflammatory cellular reaction (neutrophils, eosinophils, few lymphocytes, arrow) in the submucosa (G). in contrast, UMB administration resulted in an intact mucosa (arrow), apparent healthy goblet cells (green arrow) minimal cellular reaction in the submucosa (star) (H \&l). (H\&E x400). 

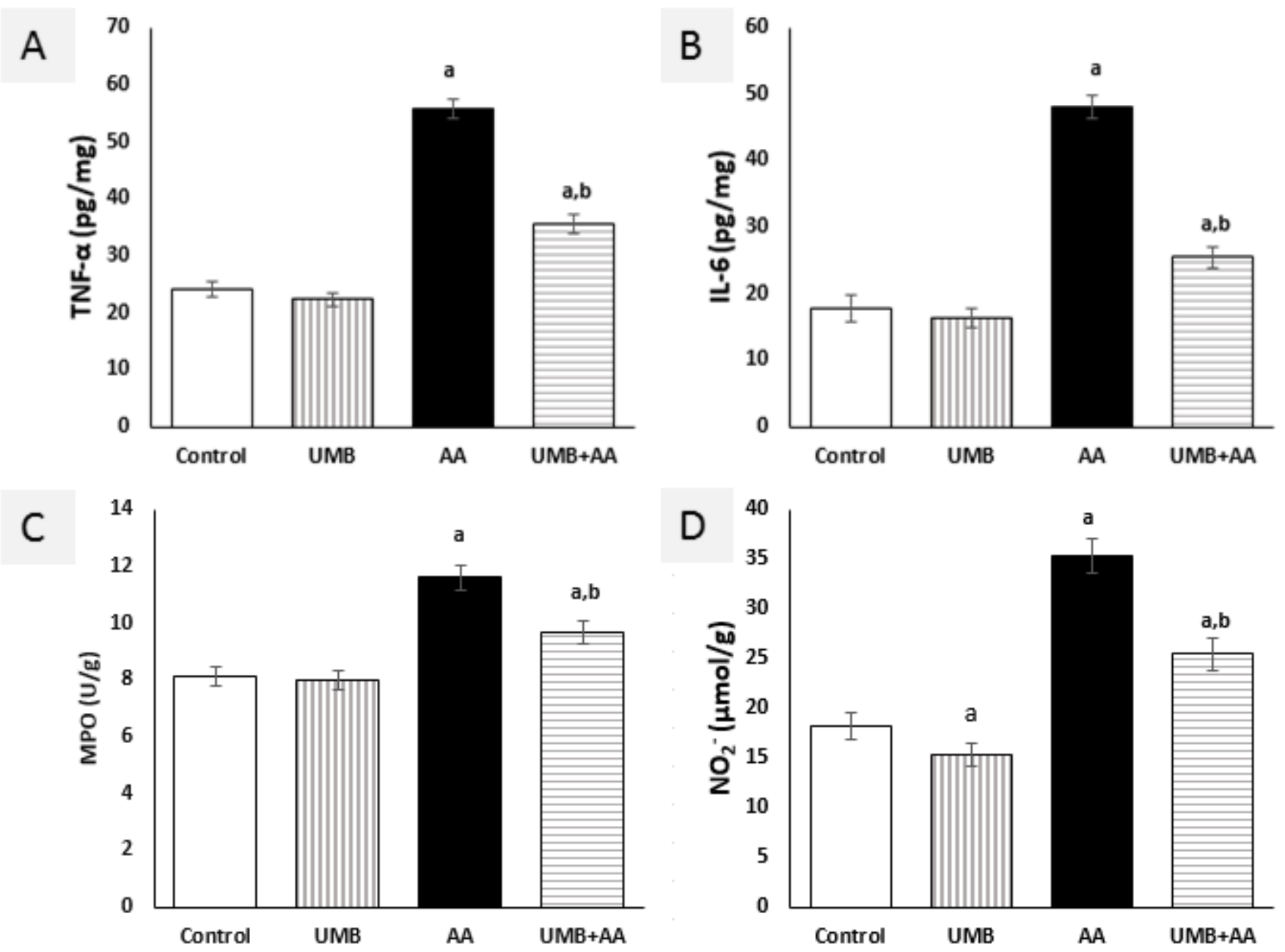

Figure 3

Effect of UMB on the inflammatory cytokines levels; TNF-a (A), and IL-6 (B) levels as MPO activity (C), and NO2- level (D) in AA-induced UC in rats. UMB: Umbelliferone; AA: Acetic acid; UC: Ulcerative colitis. Results represent mean \pm SEM $(n=10)$. aP $<0.05$ vs. control rats, $b P<0.05$ vs. AA-treated rats using Tukey's post hoc test. 

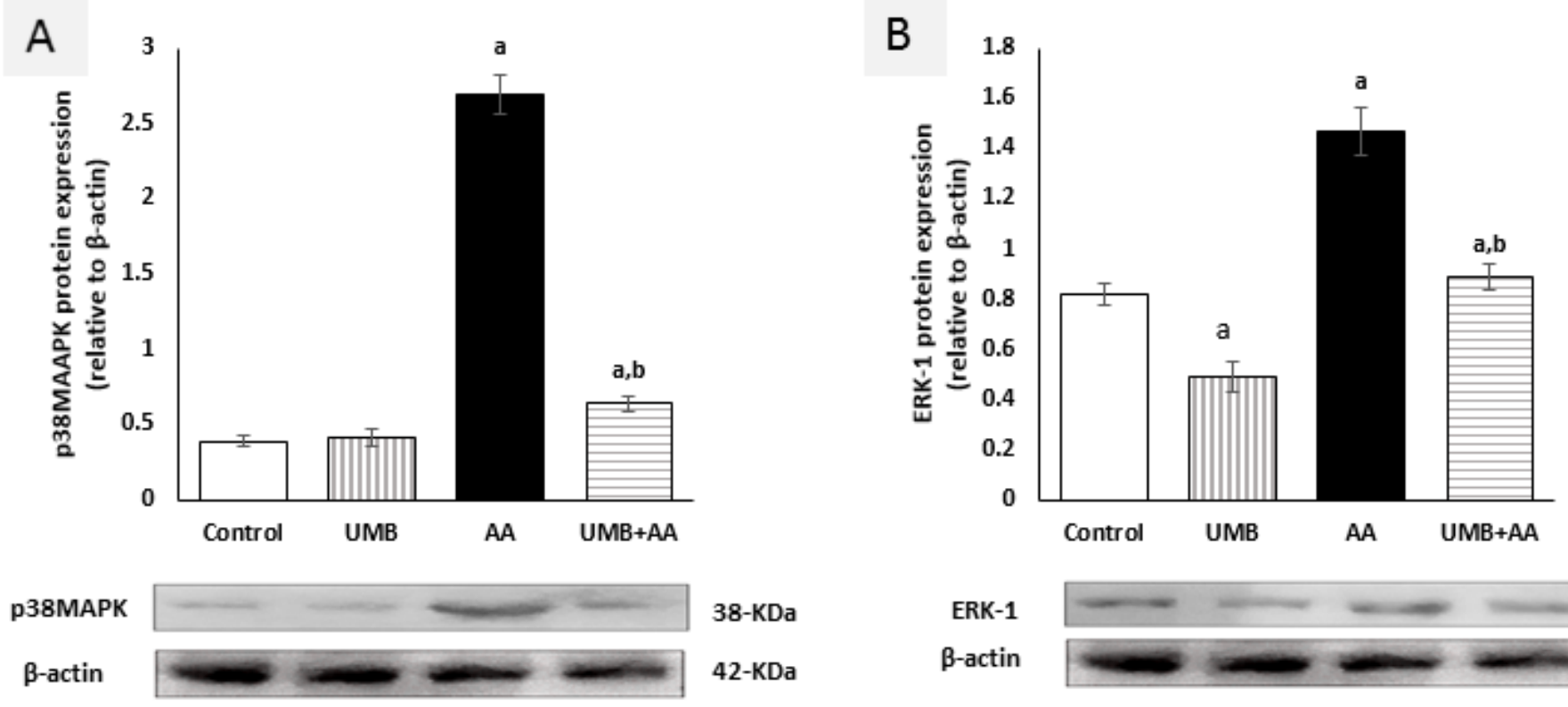

\begin{abstract}
38-KDa
42-KDa
\end{abstract}

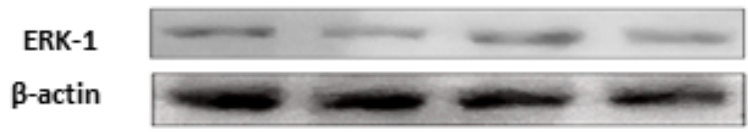

44-KDa

42-KDa

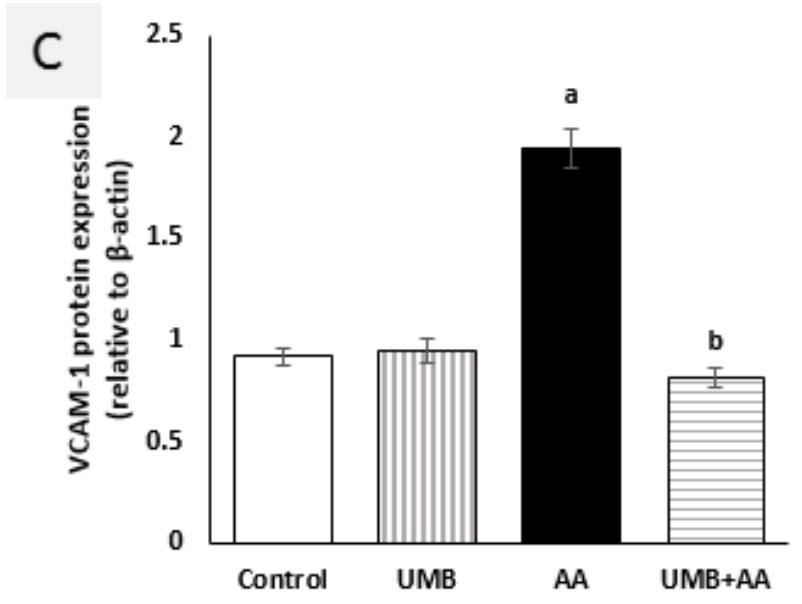

VCAM-1

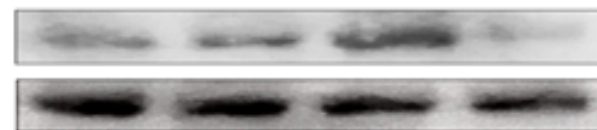

110-KDa

B-actin

42-KDa

\title{
Figure 4
}

Effect of UMB on the protein expression levels of p38 MAPK (A), ERK1 (B), and VCAM-1 (C) in AA-induced $U C$ in rats. UMB: Umbelliferone; AA: Acetic acid; UC: Ulcerative colitis. Results represent mean \pm SEM ( $n=$ 10). aP $<0.05$ vs. control rats, $b P<0.05$ vs. AA-treated rats using Tukey's post hoc test. 

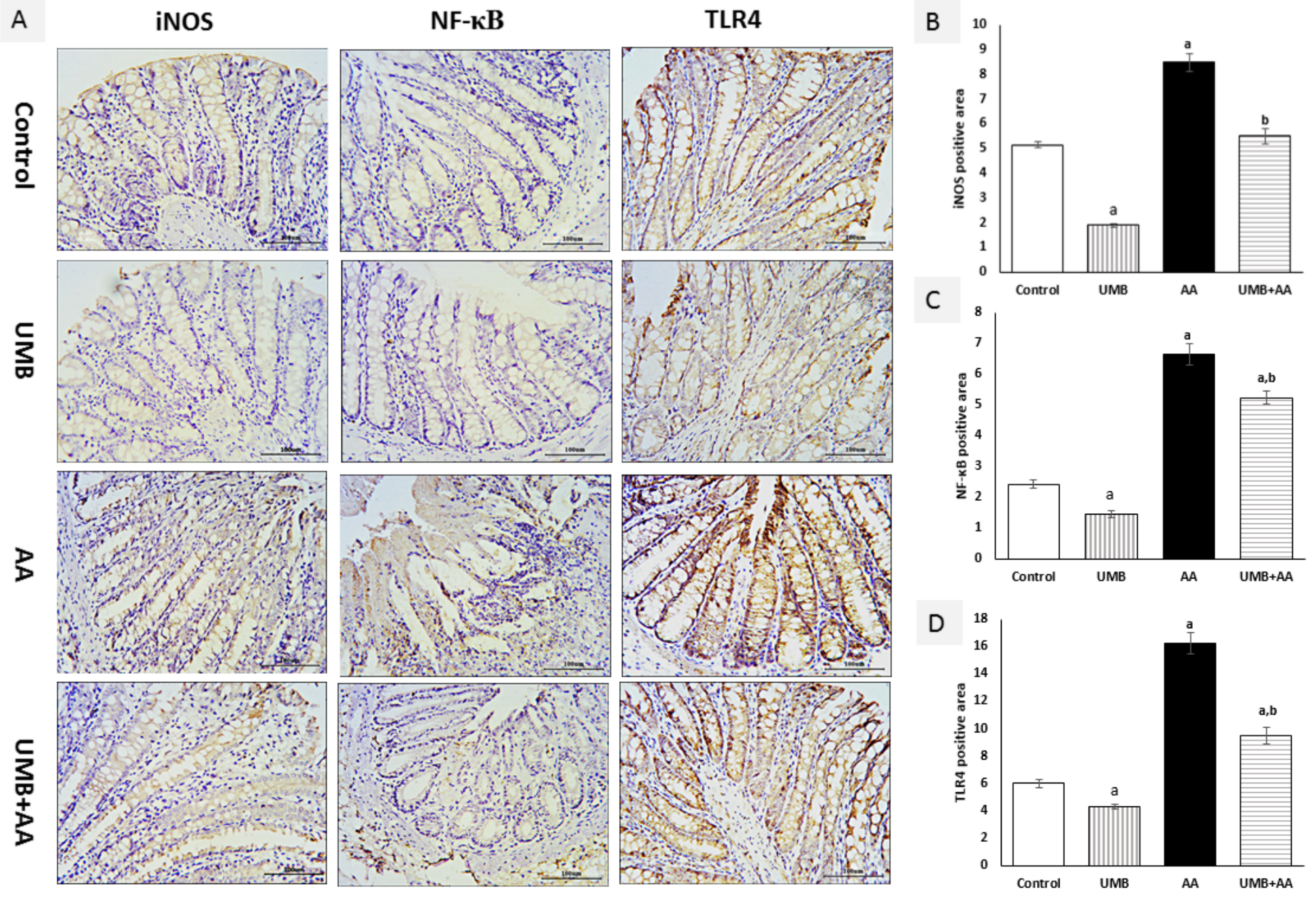

Figure 5

Effect of UMB on the immunohistochemically- assessed protein expression of iNOS (B), NF-KB(C) and TLR4(D) in AA-induced UC in rats. UMB: Umbelliferone; AA: Acetic acid; UC: Ulcerative colitis. Results represent mean \pm SEM $(n=10)$. aP $<0.05$ vs. control rats, bP $<0.05$ vs. AA-treated rats using Tukey's post hoc test. 


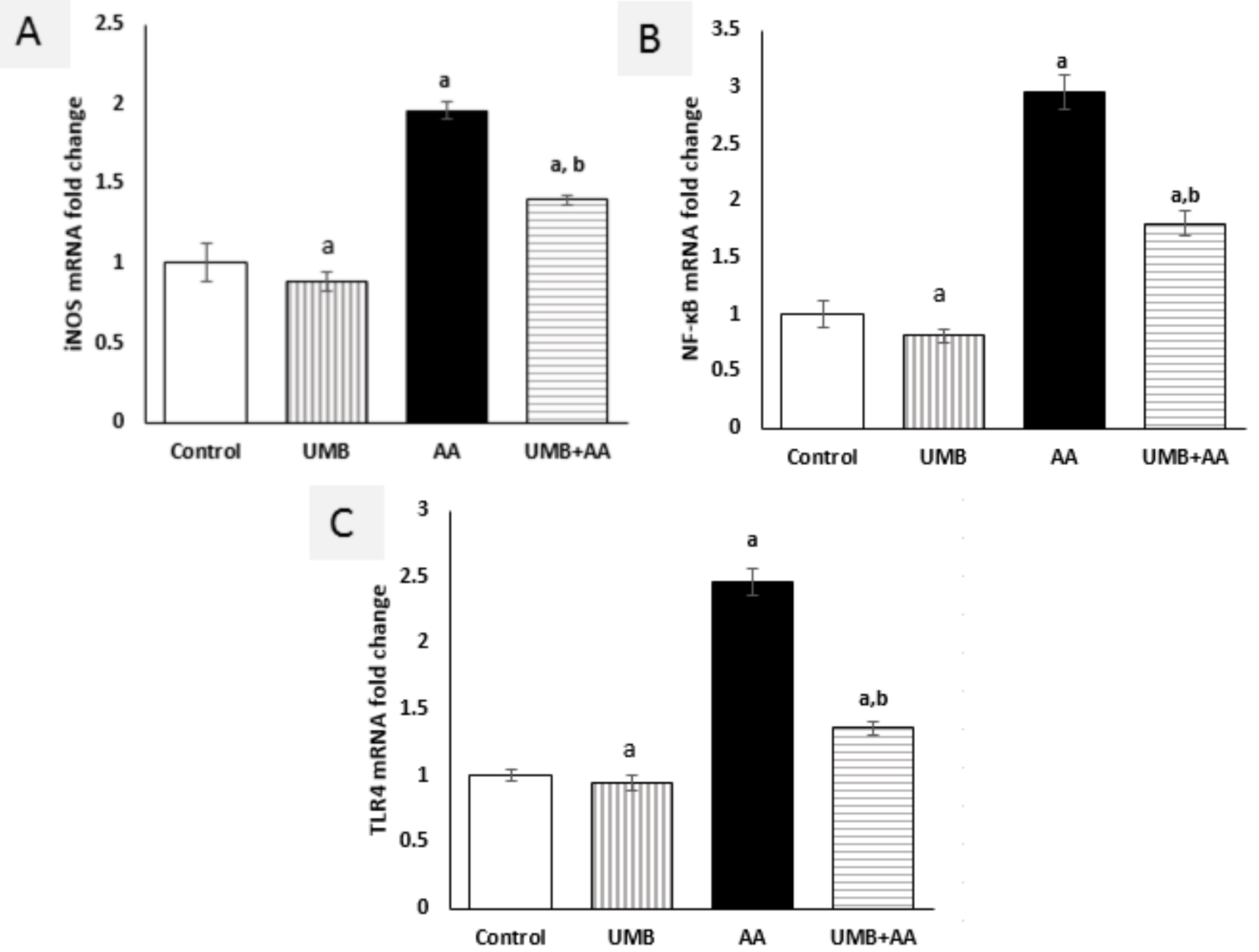

Figure 6

Effect of UMB on the mRNA expression of iNOS (A), NF-KB (B) and TLR4(C) in AA-induced UC in rats. UMB: Umbelliferone; AA: Acetic acid; UC: Ulcerative colitis. Results represent mean \pm SEM $(n=10)$. $a P<$ 0.05 vs. control rats, $b P<0.05$ vs. AA-treated rats using Tukey's post hoc test. 


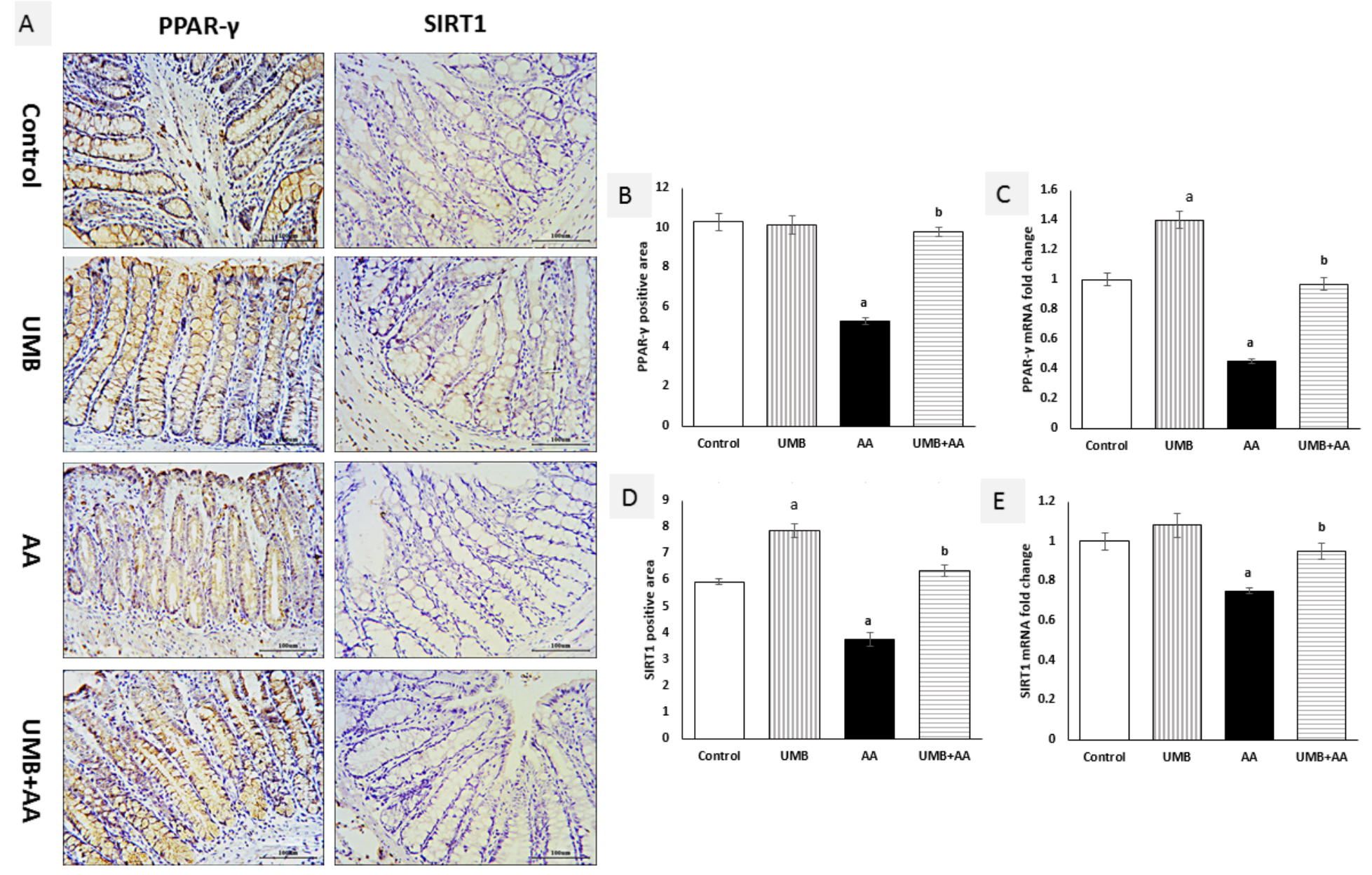

Figure 7

Effect of UMB on the immunohistochemically-assessed protein and mRNA expression of PPARY (B \&C) and SIRT1 (D\&E) in AA-induced UC in rats. UMB: Umbelliferone; AA: Acetic acid; UC: Ulcerative colitis. Results represent mean \pm SEM $(n=10)$. aP $<0.05$ vs. control rats, $b P<0.05$ vs. AA-treated rats using Tukey's post hoc test.

\section{Supplementary Files}

This is a list of supplementary files associated with this preprint. Click to download.

- ResponsetotheEditor.docx 